\title{
Prediction of subgrade soil density using dielectric constant of soils
}

\author{
Ahmed Abdelmawla \\ Graduate Research Assistant, School of Environmental, Civil, Agricultural, and Mechanical Engineering, \\ University of Georgia, Athens, USA \\ S.Sonny Kim* \\ Distinguished Faculty Fellow, School of Environmental, Civil, Agricultural, and Mechanical Engineering, \\ University of Georgia, Athens, USA
}

\begin{abstract}
Subgrade layer plays an important role to support the overlying pavement structural layers. To resist permanent deformation and failure under traffic loadings, subgrade soils are compacted to a required maximum density level during the field construction. This paper presents a simple exponential model to estimate subgrade soils density using Ground Penetrating Radar (GPR). The model was developed based on electromagnetic mixing theory to backcalculate subgrade soils density using GPR measurements. The developed model determines a soil's dielectric constant, considering dielectric and volumetric properties of the three major components of soil: air, water, and solid particles. A series of laboratory tests was conducted on six (6) soil samples at various density levels to validate the estimated densities with the measured ones. The soils density estimated by the new exponential model showed approximately $6 \%$ error than soils density measured by sand cone method.
\end{abstract}

Keywords: GPR, dielectric constant, bulk density, subgrade

\section{INTRODUCTION}

Subgrade soil is an integral part of the road pavement structure as it provides support to the pavement from beneath. The subgrade soil and its properties are important in the design of pavement structure. The main function of the subgrade is to give adequate support to the pavement structure. Therefore, the subgrade should possess enough stability under adverse climate and loading conditions. The formation of rutting and consequent cracking of pavements are generally attributed due to the poor subgrade condition.

Subgrade soils are typically characterized by their resistance to deformation under load, which can be a measure of strength (stress needed to break a material) or stiffness (the relationship of stress and strain in the elastic range or how well a material is able to snap back to its original shape and size after applying stress). The greater the resistance to deformation a subgrade shows the more the load it can support before reaching a critical deformation.

After scarifying and compacting, subgrade must be tested for compaction and checked to ensure a typical cross section and uniform grade before subsequent courses can be placed. The minimum rate of density testing for untreated subgrade material in place is one test per 1500 linear feet of roadway (full width) according to the Roadway Testing Technician 2018 Study Guide of GDOT. Before pavement Layers are placed on the subgrade, the subgrade must be 
visually checked for soft spots, depressions, etc. Passing compaction tests don't necessarily mean the subgrade is ready for the pavement. Any deficiencies must be corrected prior to placing subsequent layers.

Traditionally, quality control (QC) measures undertaken during the construction of the subgrade often check the moisture content $(w)$ and dry density $\left(\gamma_{\mathrm{d}}\right)$ of the subgrade. Therefore, $w$ and $\gamma_{\mathrm{d}}$ are the appropriate indicators of level of compaction of the subgrade at the time of construction. In some cases, Dynamic Cone Penetration (DCP), Falling Weight Deflectometer (FWD), or Light Weight Deflectometer (LWD) tests are performed to assess the stiffness of the subgrade during construction. However, these tests do not provide a direct measurement of the resilient modulus and are not commonly performed due to cost and time constraints. Another disadvantage of the traditional QC test methods is the inability of evaluating the entire compacted area. Tests at discrete locations may leave undetected soft spots on the finished subgrade. Poor quality can also have an adverse effect on pavement layers constructed on top of the prepared subgrade (1).

Pavement structure deteriorates as it receives more traffics. Thus, pavement inspection is periodically conducted. Inspection of road condition consists of two steps: First step is the visual inspection to detect cracks' locations and functional evaluation by assessing surface parameters such as roughness and skid resistance. Secondly, a structural evaluation is performed for subsurface layers, to check for decrease in thickness, lack of interlock between different layers, propagation of cracks and loss of subsurface materials (i.e., sinkholes) that might be in progress.

\subsection{Ground Penetrating Radar (GPR)}

Considering time, safety and cost-effectiveness concepts, non-destructive testing (NDT) methods are preferable than costly traditional methods such as coring and destructive testing, those approaches have been used since the beginning of the former century, but they are not accurate all the time and in some cases unsafe for the operators (e.g., on heavily crowded roads).

Usually the GPR is used effectively for several tasks on flexible, semirigid, and rigid pavement include layer thickness assessment, pavement condition evaluation, and estimation of moisture content, asphalt density gauge and compaction. The main GPR applications in tunnel inspection include thickness estimation of lining and backfill grouting, rebar localization and corrosion assessment, localization of reinforcement and cavities in lining, and estimation of moisture content (2).

Currently, GPR is also used for estimating asphalt density, for detecting defects and deteriorations in flexible pavements, and for assessing water content at different levels within the pavement structure. These applications already are at advanced level, but more research is needed; indeed, they are not yet offered/required in a systematic way, in pavement management (2).

Ground Penetrating Radar (GPR) is one of the most efficient NDT methods for subsurface monitoring. GPR is a special type of radar designed to evaluate internal inhomogeneosity and predict layer thickness of structures by penetrating the surface with electromagnetic (EM) waves. Among the various types of GPR systems, a pulsed (or impulse) GPR system is the most commercially available and commonly used to evaluate transportation infrastructure (3). The principle of the pulsed systems is that a narrow EM pulse transmitted into the ground is reflected from the interfaces of materials that have distinct dielectric properties. The most common uses of GPR in pavement engineering are to measure pavement layer thicknesses, identify large voids, detect the presence of excess water in a structure, locate underground utilities, and investigate significant delamination between pavement layers (4).

Depending on how the antennae are deployed, GPR systems are classified as air-coupled (or launched) or ground-coupled systems $(5,6)$. Air-coupled antennae are typically mounted $15 \mathrm{~cm}$ to $50 \mathrm{~cm}$ above the surface. These systems produce a clean radar signal at the pavement surface and allow for high-speed surveys of up to $65 \mathrm{mph}$. The drawbacks of air-coupled systems are their relative low penetration depth (although this could be overcome by the recent introduction of the $500-\mathrm{MHz}$ air-coupled antenna (7). 
The primary material property obtained from GPR surveys is the dielectric constant. The dielectric constant, also known as the relative permittivity, $\varepsilon_{\mathrm{r}}$, of a homogeneous media relates the relative EM velocity in a material to the speed of light in free space, $\mathrm{c}(8)$.

$$
\varepsilon_{\mathrm{r}}=(\mathrm{c} / v)^{2}
$$

Where, $\varepsilon_{\mathrm{r}}$ : dielectric constant,

$v$ : EM velocity in the material,

c: speed of light in free space of $3 * 10^{8} \mathrm{~m} / \mathrm{s}$.

The use of GPR for soil density measurements has been progressively studied, but the total research devoted to this method is minimal compared with research devoted to other applications for pavement systems. Al-Qadi et al. (9) developed three HMA bulk specific gravity models to predict in-place HMA density using GPR based on the EM mixing theory. In Malaysia, Mardeni et al. (10) developed soil density prediction tool to analyze the effect of soil density with its electrical properties using ground penetrating radar (GPR) principal at frequency range of $1.7 \mathrm{GHz}$ to $2.6 \mathrm{GHz}$. In Europe, Saarenketo (11) established a method to measure HMA pavement density using GPR. Based on the long-term studies on applying GPR for pavement quality control (QC), an exponential relationship was developed between the surface dielectric constant and the void content. In most of the previous studies, the prediction of HMA density was based on pure statistical analysis of test data. This study applies electromagnetic mixing theory to develop a prediction model for subgrade soils density.

\section{RESEARCH OBJECTIVE}

Soil is a composite material that consists of solid particles, air, and water. Density of soil depends on the specific gravities and volumetric fractions of its components. In a similar way, the dielectric constant of the soil is a function of the dielectric and volumetric properties of its components. Various EM mixing models are available to predict the dielectric constant based of a mixture on the dielectric constants and volume fractions of its components. Most of these models hypothesize that a mixture is composed of a background material with inclusions of different sizes and shapes.

The objective of this study is to develop mathematical model that can be used to predict subgrade soil dry density, based on its dielectric constant using these EM mixing formulae.

\section{MODEL DEVELOPMENT}

In accordance with the CRIM mixture theory, the dielectric constant of a homogenous mixture can be estimated by the "power-law" approximation $(9,12,13)$. A widely used class of mixing models is shown in Eq. (2).

$$
\varepsilon_{\text {eff }}^{\beta}=f \varepsilon_{1}^{\beta}+(1-f) \varepsilon_{2}^{\beta}
$$

Where:

$\varepsilon_{e f f}, \varepsilon_{i}$ and $\varepsilon_{e}$ : are the complex dielectric constants of the mixture, and the two constituents, respectively.

$f$ : the fractional volume of the first constituent (volume of first constituent/total volume).

In this mixing model, a certain power of the permittivity is averaged by volume weights. $f$ is the volume fraction and $\beta$ is a constant dependent on the mixture's composition and is usually assumed to be 0.5 (13). Assuming the total volume of soils phases is assumed as 1 as seen in Figure 1, Eq (2) can be re-written as Eq (3). 


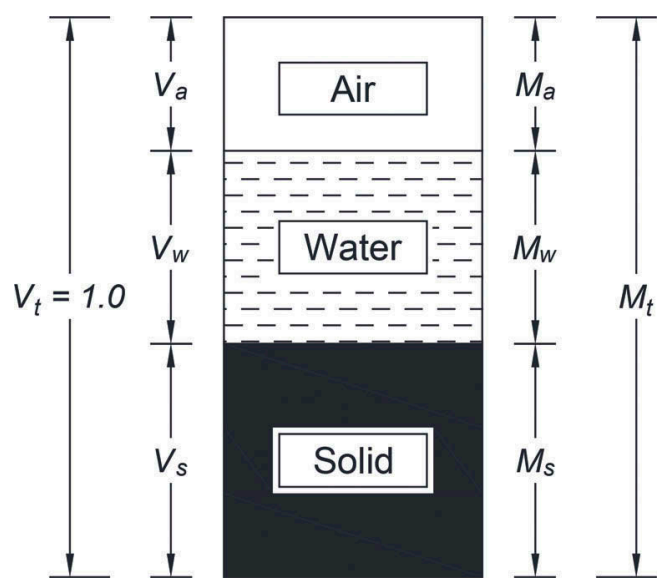

Figure 1. Soil volume and mass composition.

$$
\varepsilon_{\text {soil }}^{\beta}=V_{a} \cdot \varepsilon_{a}^{\beta}+V_{w} \cdot \varepsilon_{w}^{\beta}+V_{s} \cdot \varepsilon_{s}^{\beta}
$$

Where:

$V_{a}$ : Air voids volume in soil, $V_{w}$ : water volume in soil, $V_{s}:$ solid particles volume in soil, $M_{a}$ : Air voids mass $=0, M_{w}$ : mass of water, $M_{s}$ : mass of soilds

$\varepsilon_{\text {soil }}$ : Soil media dielectric constant, $\varepsilon_{\mathrm{a}}:$ Air dielectric constant $=1.0$, $\varepsilon_{w}:$ water dielectric constant $=80-81, \varepsilon_{s}:$ Soil particles dielectric constant

From Phase diagram relations, Assuming $V_{t}=1.0$

$$
\begin{gathered}
\because \gamma_{d}=\frac{G S \cdot \gamma_{w} \cdot\left(1-\frac{V_{a}}{V_{t}}\right)}{1+w \cdot G S}=\frac{G S \cdot \gamma_{w} \cdot\left(1-V_{a}\right)}{1+w \cdot G S}, \therefore V_{a}=1-\frac{\gamma_{d} \cdot(1+w \cdot G S)}{G S} \\
\because \gamma_{d}=\frac{M_{S}}{V_{t}}=M_{S}, \therefore \gamma_{d}=M_{S} \\
\therefore V_{w}=w \cdot M_{S} \\
V_{s}=\frac{M_{S}}{G S} \\
\varepsilon_{\text {soil }}{ }^{0.5}=V_{a} \cdot \varepsilon_{a}{ }^{1 / \alpha}+V_{w} \cdot \varepsilon_{w}{ }^{0.5}+V_{s} \cdot \varepsilon_{s}{ }^{0.5}
\end{gathered}
$$

Substituting i, ii, iii and iv in $\mathrm{v}$

$$
\begin{aligned}
& \therefore \sqrt{\varepsilon_{\text {soil }}}=1-\frac{\gamma_{d} \cdot(1+w \cdot G S)}{G S}+w \cdot \gamma_{d} \cdot \sqrt{\varepsilon_{w}}+\frac{\gamma_{d}}{G S} \cdot \sqrt{\varepsilon_{s}} \\
& \therefore \sqrt{\varepsilon_{\text {soil }}}-1=\gamma_{d} \cdot\left[-\frac{1}{G S}-w+w \cdot \sqrt{\varepsilon_{w}}+\frac{1}{G S} \cdot \sqrt{\varepsilon_{s}}\right] \\
& \therefore \sqrt{\varepsilon_{\text {soil }}}-1=\gamma_{d} \cdot\left[\frac{1}{G S}\left(\sqrt{\varepsilon_{s}}-1\right)+w\left(\sqrt{\varepsilon_{w}}-1\right)\right]
\end{aligned}
$$




$$
\therefore \gamma_{d}=\frac{\left(\sqrt{\varepsilon_{\text {soil }}}-1\right)}{\frac{1}{G S}\left(\sqrt{\varepsilon_{s}}-1\right)+w\left(\sqrt{\varepsilon_{w}}-1\right)}
$$

Note that in these equations, the specific gravity of a material is equal to the density of the material divided by the density of water at $4^{\circ} \mathrm{C}\left(1 \mathrm{~g} / \mathrm{cm}^{3}\right)$, and therefore is numerically the same as the density of the material in $\mathrm{g} / \mathrm{cm}^{3}$.

\subsection{Dielectric constant}

The dielectric constant $(\varepsilon)$ is the ratio of the permittivity of a substance to free space. The value of $\varepsilon$ in air is 1 while $\varepsilon$ in water is approximately 80 . The dielectric permittivity can be determined by measuring radio frequency reflection as it propagates through the soil. Figure 2 shows a schematic diagram of the reflections of a GPR signal from a layered system, while $A_{o}$ is the amplitude of the surface reflection and $A_{m}$ is the amplitude of the reflected signal collected over a metal plate placed on the surface.

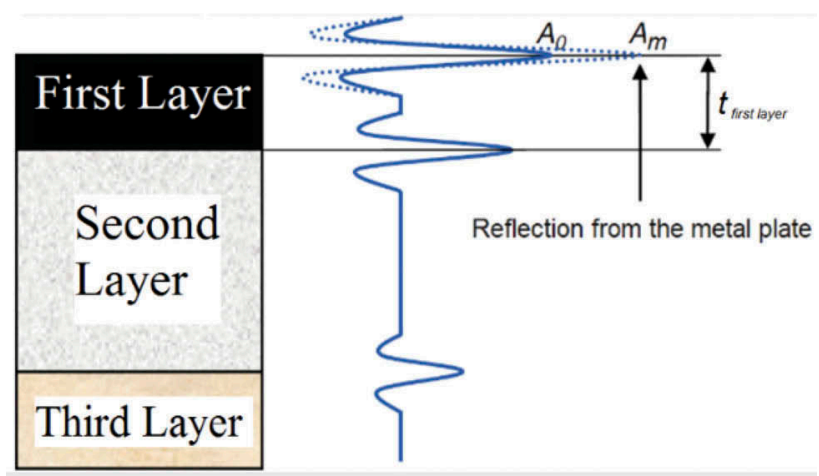

Figure 2. Schematic diagram for reflections from layer interfaces.

Where:

$\mathrm{A}_{\mathrm{O}}$ = amplitude of the surface reflection, and

$\mathrm{A}_{\mathrm{m}}=$ amplitude of the reflected signal collected over a metal plate placed on the surface.

$\mathrm{A}_{2}=$ amplitude of the reflected signal collected over second layer surface.

Eq. (5) is used to calculate the thickness $\left(\mathrm{d}_{\mathrm{i}}\right)$ of any layer:

$$
\mathrm{d}_{\mathrm{i}}=\frac{\mathrm{ct}_{\mathrm{i}}}{2 \sqrt{\varepsilon_{\mathrm{r}, \mathrm{i}}}}
$$

Where:

$\mathrm{d}_{\mathrm{i}}=$ the thickness of the $\mathrm{i}^{\text {th }}$ layer

$\mathrm{t}_{\mathrm{i}}=$ the EM wave two-way travel time through the $\mathrm{i}^{\text {th }}$ layer as shown in Figure 2

$\varepsilon_{r, i}=$ dielectric constant of the $\mathrm{i}^{\text {th }}$ layer,

$\mathrm{c}=$ speed of light in free space of $3 * 10^{8} \mathrm{~m} / \mathrm{s}$

The dielectric values of the first and second layers can be computed using the following Eqs. (6) and (7), respectively (14).

$$
\varepsilon_{1}=\left(\frac{1+\frac{\mathrm{A}_{0}}{\mathrm{~A}_{\mathrm{m}}}}{1-\frac{\mathrm{A}_{0}}{\mathrm{~A}_{\mathrm{m}}}}\right)^{2}
$$




$$
\varepsilon_{2}=\varepsilon_{1}\left(\frac{1-\left(\frac{\mathrm{A}_{0}}{\mathrm{~A}_{\mathrm{m}}}\right)^{2}+\left(\frac{\mathrm{A}_{2}}{\mathrm{~A}_{\mathrm{m}}}\right)}{1+\left(\frac{\mathrm{A}_{0}}{\mathrm{~A}_{\mathrm{m}}}\right)^{2}-\left(\frac{\mathrm{A}_{2}}{\mathrm{~A}_{\mathrm{m}}}\right)}\right)^{2}
$$

Where

$\varepsilon_{1}=$ dielectric constant for the first layer,

$\varepsilon_{2}=$ dielectric constant for the second layer

The dielectric value $\varepsilon_{n}$ for the third layer onwards ( ${ }^{\text {th }}$ layer) can be evaluated as Eq. (8):

$$
\varepsilon_{\mathrm{r}, \mathrm{n}}=\varepsilon_{\mathrm{r}, \mathrm{n}-1}\left(\frac{1-\left(\frac{\mathrm{A}_{0}}{\mathrm{~A}_{\mathrm{m}}}\right)^{2}+\sum_{\mathrm{i}=1}^{\mathrm{n}-2} \gamma_{\mathrm{i}}\left(\frac{\mathrm{A}_{\mathrm{i}}}{\mathrm{A}_{\mathrm{m}}}\right)+\left(\frac{\mathrm{A}_{\mathrm{n}}}{\mathrm{A}_{\mathrm{m}}}\right)}{1-\left(\frac{\mathrm{A}_{0}}{\mathrm{~A}_{\mathrm{m}}}\right)^{2}+\sum_{\mathrm{i}=1}^{\mathrm{n}-2} \gamma_{\mathrm{i}}\left(\frac{\mathrm{A}_{\mathrm{i}}}{\mathrm{A}_{\mathrm{m}}}\right)-\left(\frac{\mathrm{A}_{\mathrm{n}}}{\mathrm{A}_{\mathrm{m}}}\right)}\right)^{2} \text { if } \mathrm{n}>2
$$

$\gamma_{\mathrm{i}}$ is the reflection coefficient at the $\mathrm{i}^{\text {th }}$ layer interface.

$$
\gamma_{\mathrm{i}}=\frac{\sqrt{\varepsilon_{\mathrm{r}, \mathrm{i}}}-\sqrt{\varepsilon_{\mathrm{r}, \mathrm{i}+1}}}{\sqrt{\varepsilon_{\mathrm{r}, \mathrm{i}}}+\sqrt{\varepsilon_{\mathrm{r}, \mathrm{i}+1}}}
$$

Where $\varepsilon_{\mathrm{r}, 1}$ is the dielectric constant of the top layer. The dielectric constant of the second layer $\varepsilon_{\mathrm{r}, 2}$ is calculated using Eq. (7) for $\mathrm{n}$ equals 1 and using the value of $\varepsilon_{\mathrm{r}, 1}$ computed in Eq. (6). It should be noted that in the above formulation, the pavement layers are assumed to be homogeneous. Therefore, the dielectric constant of each layer is assumed to be constant in the sense that it does not vary within the layer thickness $(7,14)$.

Topp et al. (15) proposed an equation to estimate the volumetric water content $(\theta)$ in relation with dielectric constant of the soil. The water content of soil could be calculated from volumetric water content using Eqs. (10) and (11).

$$
\begin{gathered}
\theta=-0.053+0.0292\left(\varepsilon_{\text {soil }}\right)-5.5 \times 10^{-4}\left(\varepsilon_{\text {soil }}\right)^{2}+4.3 \times 10^{-6}\left(\varepsilon_{\text {soil }}\right)^{3} \\
W=\theta / \gamma_{\text {bulk }}
\end{gathered}
$$

\section{MODEL EVALUATION USING LABORATORY TESTING}

\subsection{Soil Preparation}

A soil type readily found in North Georgia were used as the subgrade material in this study. The soil index properties for these soils are provided in Table 1. The soil is classified as high plasticity silt (MH) per the Unified Soil Classification System (USCS) or A-7-5 according to the American Association of State Highway and Transportation (AASHTO) classification system.

Table 1. Soil Index Properties.

\begin{tabular}{lllll}
\hline Specific Gravity & USCS Classification & Plastic Limit & Liquid Limit & Plasticity Index \\
\hline 2.75 & MH & 37 & 57 & 20 \\
\hline
\end{tabular}


Six (6) test specimens were prepared with 1-meter long x $0.7-$ meter wide each. The soil was mixed with water till reaching desired water content for soil compaction. Then, subgrade soil specimens were constructed with $0.3 \mathrm{~m}$ (12 in.) in depth and compacted to reach six (6) different density levels. Table 2 shows the density level for each specimen. It should be noted that specimens, D1 through D5, were compacted with varing compaction efforts while D6 was not compacted at all. Therefore, it is believed that D6 specimen has a higher void ratio compared to the other specimens. After the specimens were prepared, bulk density of each specimen was measured using sand cone tests. The results of sand cone tests are presented in Table 2.

Table 2. Sand cone test results.

\begin{tabular}{|c|c|c|c|c|c|}
\hline \multirow[b]{2}{*}{ Sample } & \multicolumn{2}{|c|}{ Bulk density $\left(\gamma_{\text {bulk }}\right)$} & \multirow[b]{2}{*}{ Water content $\%$} & \multicolumn{2}{|c|}{ Dry density $\left(\gamma_{\mathrm{dry}}\right)$} \\
\hline & $\left(\mathrm{t} / \mathrm{m}^{3}\right)$ & (pcf) & & $\left(\mathrm{t} / \mathrm{m}^{3}\right)$ & (pcf) \\
\hline D1 & 1.517 & 94.710 & $22.49 \%$ & 1.238 & 77.3 \\
\hline D2 & 1.578 & 98.490 & $21.05 \%$ & 1.304 & 81.4 \\
\hline D3 & 1.304 & 81.423 & $20.43 \%$ & 1.083 & 67.6 \\
\hline D4 & 1.696 & 105.876 & $24.43 \%$ & 1.363 & 85.1 \\
\hline D5 & 1.744 & 108.877 & $26.60 \%$ & 1.378 & 86.0 \\
\hline D6 & 1.082 & 67.561 & $18.69 \%$ & 0.912 & 56.9 \\
\hline
\end{tabular}

\subsection{GPR data collection}

After sand cone tests were conducted, GPR data were collected from six (6) samples using a $2.0-\mathrm{GHz}$ air-coupled antenna. The Data acquisition system was calibrated before each scan in order to validate the signals with a perfect reflection on a metal plate. This calibration also provides some preliminary data for the data processing, with $\mathrm{A}_{\mathrm{m}}$ (amplitude of the reflected wave on the metal plate to estimate the dielectric constants for the subsequent layers) in order to calculate the density and water content ratios for the targeted samples by the GPR scan.

\section{TEST RESULTS}

Figure 3 shows the calibration of the GPR system with metal plate on top of soil specimen. From this calibration process, $A_{m}$ was found to be $7,942,173$. Using the measured GPR amplitude values from each soil specimen, dielectric constans for six (6) soil specimens were calculated using Eq. (7). Table 3 summarizes the calculated dielectric constant for each specimen.

The initial soil bulk density is calculated using Eq. (5) with an assumed gravimetric water content $(w)$ equal to $25 \%$. Volumetric water content $(\theta)$ is calculated using Eqs. (11) and (12). With Eq. (12) gravimetric water content (w) is calculated and the error between calculated and estimated gravimetric content is adjusted. Using Generalized Reduced Gradient (GRG) function, the error is minimized and recalculated for the right values through iteration process. Table 4 shows the results of the calculation process.

Table 5 shows the calculated bulk density from the model and measured bulk density from sand cone tests. Generally, the percent error ranged from 4 to $33 \%$. A substantial error with $45 \%$ was observed for the specimen with the lowest density. 


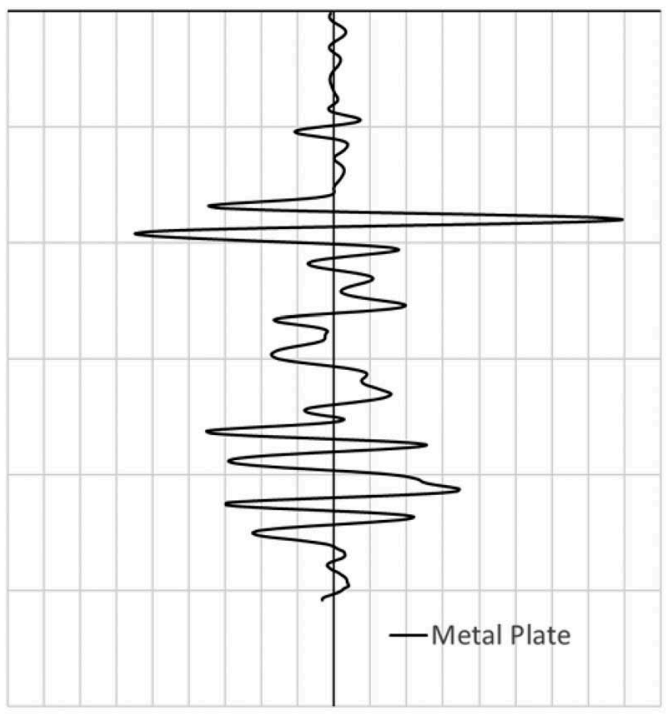

Figure 3. Metal plate calibration result.

Table 3. Dielectric constant results.

\begin{tabular}{lcc}
\hline Sample ID & Amplitude & $\varepsilon$ \\
\hline D1 & $5,257,634$ & 24.18 \\
D2 & $5,318,661$ & 25.55 \\
D3 & $4,827,136$ & 16.80 \\
D4 & $5,788,944$ & 40.67 \\
D5 & $5,740,596$ & 38.63 \\
D6 & $3,378,338$ & 6.15 \\
\hline
\end{tabular}

Table 4. Proposed model calculation results*.

\begin{tabular}{|c|c|c|c|c|c|c|c|}
\hline \multirow[b]{2}{*}{ Sample ID } & \multirow[b]{2}{*}{ w \% (Measured) } & \multicolumn{2}{|c|}{$\underline{\gamma_{\text {dry }} \text { initial }}$} & \multirow[b]{2}{*}{$\theta$} & \multirow[b]{2}{*}{ w $\%$ (Calculated $)$} & \multicolumn{2}{|c|}{$\underline{\gamma_{\text {dry }} \text { Calculated }}$} \\
\hline & & $\mathrm{t} / \mathrm{m}^{3}$ & $\mathrm{pcf}$ & & & $\mathrm{t} / \mathrm{m}^{3}$ & pcf \\
\hline D1 & $22.5 \%$ & 1.29 & 81 & $39 \%$ & $24 \%$ & 1.32 & 82 \\
\hline D2 & $21.1 \%$ & 1.34 & 84 & $41 \%$ & $24 \%$ & 1.37 & 85 \\
\hline D3 & $20.4 \%$ & 1.02 & 64 & $30 \%$ & $24 \%$ & 1.04 & 65 \\
\hline D4 & $24.4 \%$ & 1.78 & 111 & $51 \%$ & $23 \%$ & 1.81 & 113 \\
\hline D5 & $26.6 \%$ & 1.72 & 108 & $50 \%$ & $23 \%$ & 1.76 & 110 \\
\hline D6 & $18.7 \%$ & 0.49 & 31 & $11 \%$ & $17 \%$ & 0.50 & 31 \\
\hline
\end{tabular}

* $\varepsilon_{\mathrm{W}}=80(80-81), \varepsilon_{\mathrm{s}}=15(5-30) ; \theta=$ volumetric water content

Abdelmawla and Kim (16) proposed that measured density should be validated with baclculated value to reflect the soils physical properties in field. To adjust the error 
Table 5. Comprison between Proposed model and Sand cone test results.

\begin{tabular}{|c|c|c|c|c|c|}
\hline \multirow[b]{2}{*}{ Sample ID } & \multicolumn{2}{|c|}{$\gamma_{\text {dry }}$ Calc. } & \multicolumn{2}{|c|}{ Dry density (Sand Cone Test) } & \multirow[b]{2}{*}{ Error \% } \\
\hline & $\mathrm{t} / \mathrm{m}^{3}$ & pcf & $\mathrm{t} / \mathrm{m}^{3}$ & pcf & \\
\hline D1 & 1.32 & 82 & 1.24 & 77 & $7 \%$ \\
\hline D2 & 1.37 & 85 & 1.30 & 81 & $5 \%$ \\
\hline D3 & 1.04 & 65 & 1.08 & 68 & $4 \%$ \\
\hline D4 & 1.81 & 113 & 1.36 & 85 & $33 \%$ \\
\hline D5 & 1.76 & 110 & 1.38 & 86 & $28 \%$ \\
\hline D6 & 0.50 & 31 & 0.91 & 57 & $45 \%$ \\
\hline
\end{tabular}

between the calculated and measured bulk density, an exponential model was utilized as shown in Eq (12).

$$
\gamma_{\text {dry, estimated }}=\alpha\left(\gamma_{\text {dry, calculated }}\right)^{\beta}
$$

Based on the non-regression analysis, the fitting coefficients of $\alpha$ and $\beta$ were estimated as 1.051 and 0.591 , respectively. The results of the exponential method are shown in Table 6 . As a result, Eq. (14) was developed to calculate soil bulk density.

Table 6. Exponential model results.

\begin{tabular}{|c|c|c|c|c|c|}
\hline \multirow[b]{2}{*}{ Sample ID } & \multicolumn{2}{|c|}{$\gamma_{\text {dry }}$ Measured. } & \multicolumn{2}{|c|}{$\gamma_{\text {dry }}$ from Eq. (12) } & \multirow[b]{2}{*}{ Error \% } \\
\hline & $\mathrm{t} / \mathrm{m}^{3}$ & pcf & $\mathrm{t} / \mathrm{m}^{3}$ & $\mathrm{pcf}$ & \\
\hline D1 & 1.24 & 77 & 1.21 & 75 & $2.4 \%$ \\
\hline D2 & 1.30 & 81 & 1.23 & 76 & $6.0 \%$ \\
\hline D3 & 1.08 & 68 & 1.11 & 70 & $2.9 \%$ \\
\hline D4 & 1.36 & 85 & 1.40 & 87 & $2.6 \%$ \\
\hline D5 & 1.38 & 86 & 1.38 & 86 & $0.0 \%$ \\
\hline D6 & 0.91 & 57 & 0.91 & 57 & $0.0 \%$ \\
\hline
\end{tabular}

\section{CONCLUSIONS}

In this paper, the bulk density of subgrade soil was estimated using air coupled GPR systems, with antenna operating at $2 \mathrm{GHz}$ central frequencies. An exponential model was developed and tested to estimate the dry density of subgrade soil. The soils density estimated by the newly developed exponential model shows approximately $6 \%$ error than soils density measured by sand cone method. The suggested approach provides several potential benefits that may eventually rationalize its use as a method to efficiently and accurately estimate subgrade soil density based on GPR data.

\section{ACKNOWLEDGMENTS}

The work presented in this paper is part of a research project (RP 19-21) sponsored by the Georgia Department of Transportation. The contents of this paper reflect the views of the authors, who are solely responsible for the facts and accuracy of the data, opinions, and conclusions presented herein. The contents may not reflect the views of the funding agency or other individuals. The authors would like to acknowledge the financial support provided by the Georgia Department of Transportation for this study. 


\section{REFERENCES}

1. Barman, M., Nazari, M., Imran, S.A. et al. Innov. Infrastruct. Solut. 2016, 1: 23. https://doi.org/ 10.1007/s41062-016-0020-0

2. Pajewski, L., Fontul, S., \& Solla, M. "Chapter 10 - Ground-penetrating radar for the evaluation and monitoring of transport infrastructures”. In Innovation in Near-Surface Geophysics, 2019, (pp. 341398). Elsevier Inc. doi: https://doi.org/10.1016/B978-0-12-812429-1.00010-6

3. Al-Qadi, I. L. Radar Testing of Concrete: Where Are We Now. Presented at 8th International Conference and Exhibition on Structural Faults and Repair, London, 1999.

4. Advisory Circular: Use of Non-destructive Testing in the Evaluation of Airport Pavements. AC No. 150/5370-11A. FAA, U.S. Department of Transportation, 2004.

5. Lahouar, S. Development of Data Analysis Algorithms for Interpretation of Ground Penetrating Radar Data. PhD dissertation. Virginia Polytechnic Institute and State University, Blacksburg, 2003.

6. Leng, Z., I. L. Al-Qadi, J. Baek, and S. Lahouar. Selection of Antenna Type and Frequency for Pavement Surveys Using Ground Penetrating Radar (GPR). Presented at 88th Annual Meeting of the Transportation Research Board, Washington, D.C., 2009.

7. Al-Qadi, I. L., Leng, Z., Lahouar, S., \& Baek, J. In-Place Hot-Mix Asphalt Density Estimation Using Ground-Penetrating Radar. Transportation Research Record, 2152(1). 2010, 19-27. https://doi. org/10.3141/2152-03

8. Al-Qadi, I. L., Samer Lahouar, and Amara Loulizi. Successful Application of Ground-Penetrating Radar for Quality Assurance-Quality Control of New Pavements. Transportation Research Record 1861, Paper No. 03-3512, 2003.

9. Al-Qadi, I. L., and S. M., Riad. Characterization of Portland Cement Concrete: Electromagnetic and Ultrasonic Measurement Techniques. Report Submitted to National Science Foundation, Washington, D.C., 1996.

10. R. Mardeni, K. S. Subari and I. S. Shahdan, "Soil density prediction tool using microwave ground penetrating radar, 2013 Asia-Pacific Microwave Conference Proceedings (APMC), Seoul, 2013, pp. 579-581. DOI: 10.1109/APMC.2013.6694870

11. Saarenketo, T. Using Ground-Penetrating Radar and Dielectric Prob Measurements in Pavement Density Quality Control. In Transportatio Research Record 1575, TRB, National Research Council, Washington, D.C., 1997, pp. 3441.

12. Birchak J. R., Gardner C. G., Hipp J. E. and Victor J. M., "High dielectric constant microwave probes for sensing soil moisture,"in Proceedings of the IEEE, vol. 62, no. 1, pp. 93-98, Jan. 1974.

13. Sihvola, A. Electromagnetic Mixing Formulas and Applications. IEEE Publishing, London, 1999.

14. Tosti, Fabio, Alani, Amir, Benedetto, Andrea, Bianchini Ciampoli, Luca, Brancadoro, Maria Giulia and Pajewski, Lara. A comparative investigation of the pavement layer dielectrics by FDTD modelling and reflection amplitude GPR data. BCRRA Tenth International Conference on the Bearing Capacity of Roads, Railways and Airfields, 28-30 June 2017, Athens, Greece. 2017.

15. Topp, G.C., Davis, J.L., \& Annan, A.P. Electromagnetic determination of soil water content: Measurements in coaxial transmission lines. Water Resources Research, Vol. 16, No. 3, Pages 574-582, June 1980

16. Abdelmawla, A.M. and Kim, S. Application of Ground Penetrating Radar to Estimate Subgrade Soil Density. Infrastructures 2020, 5(2), 12; https://doi.org/10.3390/infrastructures5020012 